\title{
Stage Direction Role in M. I. Tsvetaeva's Romantic Plays: Semantic, Functional and Pragmatic Aspects
}

\author{
Evgeniya Leonidovna Pupysheva ${ }^{1} \&$ Alyona Alexandrovna Ivygina ${ }^{1}$ \\ ${ }^{1}$ Elabuga Institute of Kazan Federal University, Russian Federation \\ Correspondence: Evgeniya Leonidovna Pupysheva, Kazanskaya street, 89, Elabuga, 423600, Russian Federation.
}

Received: November 10, 2014 Accepted: December 1, 2014 Online Published: March 20, 2015

doi:10.5539/ass.v11n8p225

URL: http://dx.doi.org/10.5539/ass.v11n8p225

\begin{abstract}
A stage direction as a special kind of paratext gets a special refraction in the plays by Marina Tsvetaeva: it is a kind of the author's mise en scène direction. The article focuses on semantic, pragmatic and functional analysis of stage directions in the romantic plays "Blizzard" ("Metel") and "Jack of Hearts" ("Chervonniy Valet") by Marina Tsvetaeva. The authors draw particular attention to examining the pragmatic function of inter-connective, prepositional and inter-positional remarks in the analyzed plays. The topic relevance is related to the consideration of the discourse of the great poet, who plays a special place in the cultural heritage, both in Russia and abroad, as well as of polysemy and duality of stage direction representation in the romantic paradigm of M. I. Tsvetaeva's plays.
\end{abstract}

Keywords: stage directions, pragmatics, semantics, function, romantic play, Marina Tsvetaeva

\section{Introduction}

In recent years, in linguistics due to the development of new anthropocentric, cognitive and discursive paradigms and treatment of the text pragmatic component analysis, the study of the particular writer's or poet's worldview and identification of idiostyle features of the text through the study of its specific linguistic units is becoming increasingly important. One cannot say that M. I. Tsvetaeva's creativity in this sense was overlooked in linguistic research. However, despite the fact that the study of the phenomenon of M. I. Tsvetaeva's personality and her creative heritage has been subject of numerous studies both in this country and abroad (UK, USA), there has been and still is an unabated interest in her extraordinary personality and work. The most significant of the linguistic research in Russia in our opinion are the works "Marina Tsvetaeva's Poetry: Linguistic Aspect" by L. V. Zubova, "Poet and Culture: Marina Tsvetaeva's Conceptual Sphere" by V. A. Maslova, and, undoubtedly, a multi-volume "Dictionary of Marina Tsvetaeva's Poetic Language".

Among the leading English researchers studying M.I. Tsvetaeva's creative work are editors and translators (Gleb Struve, USA, Victoria Schweizer, USA, Olga Peters Hasty, USA Robin Kemball, USA, Elaine Feinstein, England), teachers and professors from the leading universities of the world (Simon Karlinsky - professor at Berkeley University and Harvard University, Michael Makin, University of Michigan, Gerald Smith, University of Oxford, England). Basically, the works of the authors mentioned above are subject to detailed coverage of M. I. Tsvetaeva's biography, mythopoetics of her creative work and the specifics of her poetic innovation. In recent years, the attention of scholars studying the phenomenon of Marina Tsvetaeva is focused mainly on the literary analysis of her poetic heritage. Among these works are the research "A Reading of Marina Tsvetaeva's Fairy-Tale Poem" by Tora Lane, "Patterns of Transcendence. Classical Myth in Marina Tsvetaeva's Poetry of the 1920s" by Hanna Ruutu and "Marina Tsvetaeva's Life and Work in the Reception of Foreign Slavic Studies" by I. K. Tsalikova.

As part of our study on the analysis of the dramatic text by Marina Tsvetaeva, we can highlight the work of M. Makin, directed at the general analysis of the content and history of the romantic plays by M. I. Tsvetaeva, who believes that they are the most "unread" works of the poet and "... represent one of the most striking evidence of the importance of the literary source of Tsvetaeva's poetics".

Thus, even now scholars studying Tsvetaeva's creative work still have many questions that require, in particular, access to a deep study of the internal design of her texts, including drama. "The drama text, - said P. Pavie - is the quicksand the surface of which periodically and differently localizes signals that guide perception, and signals that 
support uncertainty and ambiguity". These signals undoubtedly include stage directions. The content of the text represents the author's conceptual picture of the world, reflecting in the linguistic form a variety of information about the world in accordance with the author's intentions. So, the main function of stage directions is to express the author's intention. According to N. A. Nikolina, at the same time this medium of the author's voice is a means of the direct impact on the director, the actors and the reader.

\section{Methods}

In this study, while analyzing stage directions in romantic plays we used a set of methods such as description, systematization, interpretation, which suggests a comprehensive approach to the analysis of the text semantics and pragmatics and allows identification of the specificity of stage directions functioning in M. I. Tsvetaeva's discourse.

\section{Main Part}

During Marina Tsvetaeva's life none of her romantic plays had ever been staged at the theatre. This is partly due to the fact that the Marina Tsvetaeva theater is a kind of poetic experiment with a clearly cut author's basement not only in certain situations, but in all parts of the text: in the descriptions of the dramatis personae, in the stage directions, in the very specificity of the verse and in the action development. Stage directions in the plays by Marina Tsvetaeva represent an understanding of the "deep" internal sense of the author's (director's) intention.

A stage direction, or the author's remark (from French 'remarque' - remark, note), is “the author's notes in the dramatic play, which specify locale, the characters' appearance, or their spiritual image, and a variety of the characters' psychological conditions. A remark as well as action and dialogue is a characteristic feature of drama as a special kind of literature".

Multifunctional character of stage directions, formed in the 20th century drama, defined the diversity of their classifications, among which are the three main components: 1) stage directions on the content, 2) on location, 3) on the grammatical structure.

The polysemous nature of stage directions that was formed in the drama of the $20^{\text {th }}$ century defined the diversity of their classifications. The basis of our study is the classification of stage directions proposed by I. Y. Balyagina, which allows making a complete description of their functional significance and pragmatic intention (transfer of the author's evaluation, formation of the implied information) in the romantic plays by Marina Tsvetaeva.

I. Y. Balyagina distinguishes the following types of stage directions on the content and the location:

1) Situational (describing the time and place of the action);

2) Character describing;

3) Describing the events occurring to the characters;

4) Commenting, explaining the characters' statements;

5) "Director's".

The researcher also considers the list of dramatis personae and an "introductory stage direction" on place and time (given after the list of characters) as stage directions in pre-position. I. Y. Balyagina distinguishes two types of stage directions relating to the play locale:

1) Those relating to the dialogue, invading it, plugged, wedged (woven) in it;

2) Those separate from the dialogue by their position.

Stage directions detached from the dialogue by their position are divided into prepositional (those preceding the character's text) and interpositional (wedged into the dialogue though structurally detached from it).

Let us consider in more detail the semantic and functional significance and pragmatic intent of the wedged, prepositional and interpositional stage directions in the romantic plays "Jack of Hearts" and "Blizzard" by M. I. Tsvetaeva.

The plays "Jack of Hearts" and "Blizzard" were written in 1918, in a troublesome period of M. I. Tsvetaeva's life, when she was looking for new forms of self-expression. "I began to write plays", she makes an entry in her diary, "it came as inevitable, just the voice overgrew poetry, too much air was for the Flute".

The play "Jack of Hearts" ("Chervonnyi Valet") - contains in fact just two acts, brief and swift. The actors playing out the plot are not real people but playing cards. The valet - Jack of Hearts - is in love with a 20-year-old Queen of Hearts, King of Hearts' spouse. The latter goes to a military campaign; cards predict that an "amorous bed" with King of Spades awaits Queen of Hearts. The prediction comes true; Jack of Clubs and 
Jack of Diamonds, united for the sake of their kings, who claim to marry Queen of Hearts, prepare a conspiracy: they are to catch the dating lovers. The faithful Jack of Hearts warns his mistress and dies for her, pierced by Jack of Spades' lance.

A stage direction in pre-position notifying the characters and locale and/ or time of the event in the indicated plays has its own specificity. The characters of "Jack of Hearts" are playing cards, the suits of which have a symbolic meaning:

Queen of Hearts, 20 years old, blond. - Rose.

King of Hearts, an old man, grey-bearded.

King of Spades, 30 years old, black-haired.

Jack of Spades, 20 years old, black-haired.

Jack of Clubs, 40 years old, red-haired.

Jack of Diamonds, 20 years old, black-haired.

Jack of Hearts, a boy, blond.

The actors' costumes are of the suit colour, except the Spades, which are all black. The Queen and the Kings are in large cloaks, Jacks in short - like wings - capes. The Jack of Hearts' lute and the Jack of Spades' sharp lance are in the shape of the heart.

This stage direction is polysemous: it becomes a form of the author's artistic intent embodiment, which is significant to the construction of the whole text. Cards-people or people-cards, telling fortune, predicting fate, prison, keen interest or an amorous bed, love and death act in either real or unreal chronotope. This "card-game" is highlighted by an appropriate stage direction indicating stage costumes the colour of the card suit.

The play "Blizzard" ("Metel"') has the same romantic flavor, the same kingdom of love dates and fatal partings at the strange crossroads of life, and Lady reminds of Alexander Blok's mysterious woman-stranger. The main characters in "Blizzard" - he (Mr.) and she (Queen) - remain unknown to each other and the audience.

The prepositional stage direction in the play "Blizzard" gives a metaphorical and at the same time concise characterization of the five dramatis personae:

Lady in a raincoat, 20 years old, a bit adolescent.

Man in a cloak, 30 years old, blond.

Old woman, totally $18^{\text {th }}$ century.

Innkeeper\}

Merchant $\}$ each - personification of his occupation.

Hunter\}

As we can see, in both plays M. I. Tsvetaeva using traditional installation of prepositional stage directions, brings her vision of the characters of the play, with an emphasis on specific, but important for the subsequent plot details: social status (Lady, Queen, King), trade (Hunter, Innkeeper, Merchant), heroes' age (Lady, 20 years old, Jack of Hearts, 20 years old, King of Spades, 30 years old), characteristic features of appearance (grey beard) and clothing (coat), hair colour (blond, red), she gives a brief but bright characteristics of an image (Old woman, totally $18^{\text {th }}$ century, Innkeeper \& Merchant\} each - personification of his occupation).

In the play "Jack of Hearts" such details are made more concrete with the plot development. So, in the pre-positional stage direction at the beginning of the play Jack of Clubs' his age (40 years old) and hair colour (red) are indicated. When he appears before Queen and Jack of Hearts his appearance and behaviour are conspicuously negative: Enter Jack of Clubs. About 40 years old. Shaven, short, square. Black clubs' bow-knots are on the white shoes. A black shamrock is in his hand.

There are no such concrete details in the play "Blizzard" as there is practically no action in the usual sense: it is founded on the dialogues about feelings and the atmosphere of half-dream. It is only the playwright's stage directions that indicate the genre of the text.

Thus, the list of characters in the pre-positional (poster) stage direction containing the author's characteristics gives the reader a full view of the author's approach to the stage implementation and of the hidden conflict of the play.

Words denoting colour used in the prepositional stage direction of the play "Jack of Spades" get a symbolic 
meaning. Blond Lady and Blond Jack stand as symbols of purity and innocence only at the beginning of the play, as the action proceeds the Lady puts on a huge black necklace and matching bangles. Such a sharp change of colours symbolizes the transformation of the blond innocent Rose into a treacherous woman, obedient only to their passions, forgetting her sense of loyalty to the King. The King of Spades', Jack of Spades' and Jack of Clubs' black clothes symbolize the characters' treacherous schemes, evil and betrayal.

Jack of Spades (twitching - nearly dancing)

Cloak is black and eye is black.

Black from head to foot. In black veins poison flows,

Hell.

The spade's sharp end is

My black heart

The significance of the words denoting colour in the play "Blizzard" is slightly reduced: only once the author focuses attention on the Lady's green cloak. The green colour of the cloak is an allusion to Marina Tsvetaeva's colour of the eyes. The indirect proof of it is the actors' words after the author read the play: "But who will be acting the Lady in a raincoat ... (I to myself: Lady in a raincoat is my soul, whom nobody can act.)".

The descriptive stage direction that indicates Jack of Hearts' and Jack of Spades' lances and lutes in the shape of the heart causes additional semantic associations (the lance is death, evil and the lute is music and love), and determines the tragic end: the lute is broken, and Jack of Hearts, who was faithfully though hopelessly in love with his Fair Lady, is killed by a lance.

Lady, aged 20, is a character in both plays: but in "Jack of Hearts" she is Lady - Rose, beautiful and at the same time frivolous and fickle, while in "Blizzard" - she is a woman, who suffered a lot but yet have not lost hope for the true love.

Lady

My armour is Love, with it I will start

My way in any weather!

Lady

(with growing passion)

Today in the morning opening my window,

Where like raged angel the blizzard was raging...

You will be laughing, - all the same!

I understand that I am not in love with my spouse!

I am keen on going there into the blizzard...

The prepositional, "introducing" stage direction of space-time points to the chronotope of the events described in the play in the most general terms. There is no direct reference to a specific place and time of the event in the play "Jack of Hearts"; the play "Blizzard" gives such a specification: "The action takes place on the New Year's night of 1830 , in the tavern, in the forests of Bohemia, in a blizzard".

Prepositional by the place in the drama stage directions usually coincide with the situational stage directions by their functional classification. Characterizing the time and place of action, or a situation in which things are going, they fix a static position of objects on the stage. The play "Blizzard" contains two prepositional situational stage directions describing the place of events in the play: "Tavern. The fireplace is glowing. Merchant and Hunter talk at a round oak table. A short distance away, in the large lonely chair sits the Old Woman. At the window, in an unbuttoned green cloak, Lady looks into the blizzard". We should mention that the second stage direction specifies the change of the characters' locale: Merchant and Hunter have gone. Innkeeper is clearing the table. Lady is at the window just as before. Old Woman is in the armchair as before.

In the play "Jack of Hearts" the situational stage direction is changed several times, determining the dynamics of action: it is the throne room at the beginning of the play, the royal garden, a gazebo in the garden: "Throne Room. Lady is on the throne. Near her his back bolt upright, with a lute in hand, is Jack of Hearts. Opposite them with a huge sword at the waist sits King of Hearts". "Night. Royal Garden. A huge round tree in bloom. On the left, in the corner is a garden gazebo ... ". "Jack wrapped in a cloak, on the stairs, in the gazebo, sings. 
It is necessary to note that the author combines in a single unit the situational stage directions and the directions describing the characters' actions, mentality and behaviour, such as Jack of Hearts' faithfulness is highlighted by the phrase: Beside her, bolt upright, with the lute in his hands, is Jack of Hearts.

The scenic space of the play is able to expand, in the first place, by the sounds in the situational post-positional stage direction in the play "Jack of Hearts": "the sound of tambourine, horses' hoofs far away". Secondly, a pointer to the space outside the stage is a window facing the "blizzard", "jingle bells receding irretrievably" (the play "Blizzard").

Interpositional stage directions describe the characters and their actions, their behaviour and voice modulation. For example, in the play "Jack of Hearts" there are the following stage directions: Lady on the throne; Lady tilts her head; Lady comes down from the throne and squats; Lady crouches low. These remarks indicate Lady's social status and behaviour, complying with the requirements of etiquette at the time of parting with the old King: with the story development her manners and voice modulation change: "Lady sitting on the throne; is singing; while singing absent-mindedly lays cards; Lady coyly, laughing, with increasing fervor. At a meeting with King of Spades: The lady looks up - her eyes half closed - like a post - a lunatic - goes to meet him".

The interpositional stage directions indicate the characters' inner emotional state: Jack of Spades (in rage, irritated); Jack of Clubs (frightened); Lady (frightened, feverishly, spiritedly); Jack of Hearts (haughtily, stone-like, in false solemnity); Jack of Spades (flattering, decisively, irritated, in a frenzy).

In the play "Blizzard" a sharp discrepancy between the Lady's outer coldness and inaccessibility and her internal mental anguish is reflected in the following stage directions: "The lady looks in a blizzard, looking out of the window, still by the window", its emotional component is reflected only in one stage direction: Lady (like ice).

A special role is played by the interpositional stage directions specifying the characters' gestures and facial expressions which have unconditional communicative significance in understanding the specifics of their content in these plays: Jack of Hearts (crookedly smiling, bowing, stepping back, pushes the broken lute with his foot); Jack of Clubs (throwing up his hands, hunching his shoulders); Jack of Diamonds (hugs, wants to kiss, pointing to his clothes); Lady (click him on the nose, slightly leaning on his shoulder). The play "Blizzard" which is structurally more complicated shows a minimum of the gestures and facial expressions and is connected with the image of one character only: Gentleman (quietly taking her hands and leaving them in their own, putting both his hands on her head).

The key to the stage implementation are interpositional "musical" stage directions: Lady, sitting on the throne, is singing; Jack, moving the table, puts two candles, places the cards. Singing gives out the cards; Jack of Hearts sings a song of love and farewell before his tragic death at the end of the play. M.I. Tsvetayeva draws attention to the stage directions indicating the characters' voice intonation: Jack of Clubs (stridently as the learned lesson), Gentleman (in a singsong voice).

In some cases, the interpositional stage direction may have a different pragmatic intent. In the play "Jack of Hearts" the remark "dumb" is used twice (which is an allusion to Nikolai Gogol's comedy "Inspector General"). But in the first case, the dumb scene is the culmination of the story: Lady's fateful encounter with King of Spades. In the second case it refers to the final scene of the play - the murder of Jack of Hearts:

Dumb

Jack of Clubs with a lantern. Following him - from a distance - Jack of Diamonds in a mask.

Jack of Clubs bends the lantern to Jack of Hearts' face. Jack of Diamonds protruding his neck puts his finger to the lips.

Curtain.

In the play "Blizzard" the interpositional stage direction "dumb" is not expressed graphically, but is contextually played on by the author: Lady and Lord meet by chance on the New Year Eve, break up early in the morning. The unreality of what is happening is heightened by a dream motif in the postpositional remark: In the room - a dream. Jingle bells are receding irretrievably.

The dream motif is played out in the dialogue of Gentleman and Lady at the time of the meeting and of farewell:

Lady

(as if in a dream)

Somewhere I saw your eyes,

I heard somewhere your voice. 
$<\ldots>$

Lady (as if in a dream)

Sleeping.

$<\ldots>$

Gentleman

And in the desert princely rooms

High Moon will go...

(Looking at her sleeping persistently and gently).

The pragmatic orientation of stage directions is associated primarily with the orientation of the play towards staging at the theater (the play has as it is two lives in art: the actual literary and theatrical), for as K.S. Stanislavski said: "Only on the stage of the theater one can find stage work in its entirety and essence".

The "director's" stage directions (and they always will be interpositional judging by the place in the text of the play) can include:

1) the ones describing the motion of the curtain (the play "Jack of Hearts");

2) stage directions such as "Pause", "Silence", etc., positioned among the characters' replicas and formalized as occupying a separate position:

Lady

For the late wanderers my toast!

Gentleman

(emphatically)

For early pilgrims!

Complete silence.

Gentleman

(continuing)

In the men's coat ... - like a disgraced queen -

Into a furious blizzard - from the blizzard of ball!

Silence.

All the lies called you back

All blizzards fought for you

3) the ones indicating the characters' location (i.e., those referring only to the mise en scène): they include the arrangement of the actors in prepositional stage direction, interpositional and inserted playwright's remarks, indicating the character location at the time he is uttering the replica:

Gentleman

You're a woman, you remember nothing...

You do not remember! ... Do not have to ...

(Goes to the door. Stops at the door.).

Gentleman

A whirlwind brought me,

A whirlwind will carry me away

(Lady with his appearance went onto a low bench, to the fire).

At the climax of the play the placement of the actors on the author's intention changes again: Gentleman and Lady. - The lady is on the bench, everything she says sounds like from the bottom. Separated from her by the turning of the table at the end of the wall bench is Gentleman. Everything he says sounds as if from above. Both have not removed raincoats. Old Woman in the chair is immobile.

Stage directions of this kind are numerous in the play "Blizzard" where the events take place in the inn thus 
adding dynamics to the events.

In the "Jack of Hearts they are not numerous:

Jack of Spades

Clubs, what do you think?

Jack of Clubs (coming out from behind the tree).

$<\ldots>$

Lady

It's time! Goodbye! Do you hear the clatter from the black thickets?

(Runs, running, drops the cloak. Jack, raising it, drops the lute. It is broken).

\section{Results}

Thus, all the qualities of stage direction cause, on the one hand, their pragmatic orientation; on the other hand, they determine the adequacy of the play interpretation.

All the macrostructure of M. I. Tsvetaeva's stage direction texts is polysemous and is a kind of leitmotif of the author's intention and staging (the theme of the snowstorm, the theme of the dream). Every word of the stage direction, correlated with the main text of the play, responds to the main challenge revealing the characters' psychological images.

\section{Inferences}

The analysis of stage directions in the plays by Marina Tsvetaeva allows concluding that the convergence of the drama with lyric-epic work generates a special form where the "director's" general stage directions are minimal and may not be taken into consideration, and M. I. Tsvetaeva's plays are a vivid proof to it. All stage directions are significant here, even those creating a mise en scène and placing characters, are in a certain way involved in the disclosure of the dramatis personae. Moreover, evaluation tools, the means of expressing subjective modality, individual author's figures of speech are widely and consistently used in stage directions; boundaries between prose and drama are erased; a stage direction becomes polysemous and serves as one of the components of the text imagery; therefore it requires careful and thorough study.

\section{References}

Balyagina, I. J. (2001). On the classification of stage directions. Russian language and literature: Questions of history and the current state of teaching methods at the university and school. All-Russian Scientific Conference of Russian linguists: in 3 parts. Part One, pp: 211-213.

Dictionary of Marina Tsvetaeva's Poetic Language. Compiled by M/Y/Belyakova, M. P. Olovyannikova, O. G. Revzina. In 4 Vol. Moscow: House-Museum of Marina Tsvetaeva, 1996 - 2002.

Feinstein, E. (1987). A Captive Lion. The Life of Marina Tsvetaeva (p. 289). London: Hutchinson.

Hasty, O. P. (1996). Tsvetaeva's Orphic Journey in the Worlds of the Word (p. 267). Evanston; Illinois: Space as Categories of Text: A Theory and Northwestern University Press.

Karlinsky, S. (1966). Marina Tsvetaeva. Her Life and Art (p. 299). Berkeley; Los Angeles.

Karlinsky, S. (1985). Marina Tsvetaeva. The woman, her world and her poetry (p. 289). Cambridge.

Kemball, R. (1982). Innovatory Features of poetry of Tsvetaeva's Lyrical Verse (pp. 79-100). Russian Literature and Criticism. Berkeley.

Kostelyanets, B. O. (1976). Drama and Action. Lectures on Theory of Drama (p. 226). Leningrad: Academy of Sciences of the USSR.

Lain, T. (2009). A Reading of Marina Tsvetaeva's Fairy-Tale Poem (p. 152). Stockholm: Universitetsservice AB.

Makin, M. (1993). Marina Tsvetaeva. Poetics of Appropriation (p. 335). Oxford: Clarendon Press.

Makin, M. (1997). Marina Tsvetaeva. Poetics of Comprehension (p. 310). Moscow: House-Museum of Marina Tsvetaeva.

Maslova, V. A. (2004). Poet and Culture: Marina Tsvetaeva's Conceptual Sphere (p. 256). Moscow: Flinta: Nauka.

Nikolina, N. A. (2003). Philological Analysis of Text (p. 256). Moscow: Academia. 
Pavie, P. (1991). Dictionary of Theatre (p. 504). Moscow: Progress.

Ruutu, H. (2006). Patterns of Transcendence. Classical Myth in Marina Tsvetaeva's Poetry of the 1920s (p. 158). Helsinki: Helsinki University Printing House.

Schweitzer, V. A. (1992). Marina Tsvetaeva's Life and Genesis (p. 544). Moscow: Interprint.

Smith, G. (1978). The Versification of Russian Émigré Poetry 1920-1940. The Slavonic and East European Review, $1,32-46$.

Struve, G. P. (1956). Russian literature in exile: The experience of foreign literature historical review (p. 419). New York: Chekhov.

Timofeev, L. I., \& Turaev, S. V. (1985). In L. I. Timofeev, \& S. V. Turaev (Eds.), Concise Dictionary of Literary Terms: Book for Students (2nd ed., p. 137). Moscow: Education.

Tsalikova, I. K. (2005). Marina Tsvetaeva's Life and Work in the Reception of Foreign Slavic Studies: England, USA: Cand. Science Thesis. Ishim, 224.

Tsvetaeva, M. I. (1988). Theatre (p. 342). Moscow: Iskusstvo.

Zubova, L. V. (1989). Marina Tsvetaeva's Poetry: Linguistic Aspect (p. 263). Leningrad: LSU.

\section{Copyrights}

Copyright for this article is retained by the author(s), with first publication rights granted to the journal.

This is an open-access article distributed under the terms and conditions of the Creative Commons Attribution license (http://creativecommons.org/licenses/by/3.0/). 